\title{
Mechano-morphological studies of polyamide 6 based single polymer laminate composites prepared by different reactive processing techniques
}

\author{
Shafagh Dinparast Tohidi ${ }^{\mathrm{a}, *}$, Zlatan Z. Denchev ${ }^{\mathrm{b}}$, Ana Maria Rocha ${ }^{\mathrm{a}}$, Nadya V. Dencheva ${ }^{\mathrm{b}}$, \\ Bernhard Engesser ${ }^{c}$, A.S. Pouzada ${ }^{\mathrm{b}}$ \\ ${ }^{\text {a }}$ Center of Textile Science and Technology (2C2T), Department of Textile Engineering, University of Minho, Guimarães, Portugal \\ ${ }^{\mathrm{b}}$ Institute for Polymers and Composites (IPC), Department of Polymer Engineering, University of Minho, Guimarães, Portugal \\ c Jakob Müller AG, Frick, Switzerland
}

\section{A R T I C L E I N F O}

\section{Keywords:}

Single polymer composites

Polyamide 6

Woven reinforcement

Reactive processing

Tensile properties

Recycling

\begin{abstract}
A B S T R A C T
Single polymer laminate composites based on polyamide 6 (PA6) were prepared by two methods: (i) reactive injection molding and (ii) powder coating/compression molding, both carried out in the presence of PA6 woven textile plies. The effect of the textile volume fraction $V_{f}$ on the tensile properties of all composites was investigated. The laminates obtained by powder coating/compression molding displayed best mechanical performance, whereby in the composites with $V_{f}=15 \%$, the improvement of the elastic modulus reached $98 \%$ in respect to commercial hydrolytic PA6 reference, or $50-86 \%$ as compared to neat anionic PA6 samples. Polarizing light microscopy with image processing was used for morphological characterization. A transcrystalline layer at the fiber-matrix interface was detected in all laminates with thicknesses between 0.5 and $3.0 \mu \mathrm{m}$, depending on the preparation technique applied. The thermal stability was studied in the temperature range of $30^{\circ} \mathrm{C}-550^{\circ} \mathrm{C}$. The laminates obtained by reactive injection molding displayed the lowest initial decomposition temperature due to the presence of oligomers. Selected laminate composites were reprocessed by grinding and injection molding. The recycled composites obtained by powder coating displayed a $38 \%$ increase of the elastic modulus in respect to commercial hydrolytic PA6 thus confirming the sustainability and recyclability of PA6-based single polymer composites.
\end{abstract}

\section{Introduction}

Conventional thermoplastic composites (TPC) are produced by combining chemically different matrix and reinforcement components. TPC that can be processed by heating the polymer matrix above a certain temperature. With respect to the upcoming environmental legislation, TPC need to be properly recycled to ensure energy saving and avoid environmental pollution [1]. Recycling of TPC is complex since it is costly and related with certain technical difficulties and negative environmental impact [2]. Constant efforts are being made to prepare better recyclable conventional TPC so as to boost their efficient reprocessing [3-5].

The single polymer composites (SPC) were introduced several decades ago by Capiati and Porter [6] as an alternative of the conventional thermoplastic composite materials. While in the latter, the matrix and the reinforcement components are typically quite dissimilar, in the SPC both are made of the same polymer. With time, this SPC concept was extended to almost all commercial polymers bringing forward two main beneficial effects: (i) increase of the interfacial adhesion due to the possibility of $\mathrm{H}$-bonds or even covalent bonding across the interface $[7,8]$ and (ii) full recyclability by reprocessing with a clearly positive environmental influence [4], which is in accordance with the upcoming environmental legislation $[9,10]$. These findings have stimulated the interest toward new developments related to SPC materials based on commercial thermoplastic, including polyamides.

Polyamide 6 (PA6)-based SPC are typically prepared by melt-processing techniques that may include powder impregnation [11], hot compaction [12,13], overheating of fibers [14], film-stacking [15], and co-extrusion [16]. All these techniques require partial melting of prefabricated reinforcing polymeric elements in order to create the isotropic matrix, whereby often the processing window does not exceed $5{ }^{\circ} \mathrm{C}$. This constitutes a typical drawback of all methods for SPC preparation involving melt processing because of the easy loss of orientation of the reinforcements. Furthermore, thermal degradation of the latter frequently occurs. These two factors unavoidably lead to insufficient mechanical properties of the final composites [16].

\footnotetext{
* Corresponding author.

E-mail address: id4618@alunos.uminho.pt (S. Dinparast Tohidi).
} 
Table 1

Sample designation and properties of plain-woven reinforcements.

\begin{tabular}{|c|c|c|c|c|c|c|c|c|}
\hline Type & Treatment & Designation & Density $^{\mathrm{a}}$ & Areal weight (g.m $\left.{ }^{-2}\right)$ & Thickness (mm) & Elastic modulus $^{\mathrm{b}}(\mathrm{MPa})$ & Tensile strength ${ }^{\mathrm{b}}(\mathrm{MPa})$ & Tensile strain at break ${ }^{\mathrm{b}}(\%)$ \\
\hline \multirow[t]{2}{*}{ Plain } & No & $\mathrm{P}$ & $22 \times 16$ & $147.6 \pm 1.7$ & $0.58 \pm 0.01$ & $0.8 \pm 0.1$ & $15.4 \pm 0.8$ & $67.2 \pm 0.7$ \\
\hline & Yes & P-A & $20 \times 12$ & $111.0 \pm 2.1$ & $0.42 \pm 0.01$ & $21.7 \pm 1.1$ & $19.4 \pm 1.0$ & $28.1 \pm 1.0$ \\
\hline
\end{tabular}

${ }^{\text {a }}$ Density $=$ Warp filaments.cm ${ }^{-1} \times$ Weft filaments. $\mathrm{cm}^{-1}$.

b Tensile properties are measured in warp $\left(0^{\circ}\right)$ direction of plain-woven reinforcement.

Attempts were made to widen the processing window of the conventional techniques for SPC preparation [15,17-20]. Bhattacharyya et al. [15] combined hot compaction and film stacking to prepare PA6 based SPC. In them, melt-quenched PA6 film was used as matrix component and high tenacity PA6 filament as reinforcement. All reinforcements were treated with $\mathrm{Sb}_{2} \mathrm{O}_{3}$ to improve the interfacial adhesion via trans-reactions. This caused an improvement on tensile stiffness and strength up to $32 \%$. However, the processing window was only $2{ }^{\circ} \mathrm{C}$.

By means of in-mold activated anionic ring opening polymerization (AAROP) in the presence of PA6 plain woven fabrics and reactive injection molding (RIM) Gong et al. [17] prepared PA6-based SPC achieving tensile strengths of $150 \mathrm{MPa}$ of the final laminate. Subsequent work by Dencheva et al. [18] described the preparation and SPC material obtained via in-mold AAROP in the presence of continuous aligned PA6 textile fibers using a semiautomatic prototype RIM equipment. Using only $20 \mathrm{wt} \%$ of fibers, tensile strength of $130 \mathrm{MPa}$ and Young's moduli above 1.6 GPa were obtained.

More recently, Tohidi et al. [19] prepared SPC laminate composites (designated as KSPC) via compression molding of PA6 knitted textile structures and PA6 microparticles obtained by solution-precipitation AAROP of ECL. The tensile properties of these KSPC were studied as a function of the knitted reinforcement architecture, fiber volume fraction, ply orientation and stacking orders. The best properties in tension were shown by KSPC with $15 \mathrm{vol} \%$ fiber content, i.e., improvements of $11 \%$ and $87 \%$ as compared to the neat anionic PA6 matrix and to commercial hydrolytic PA6, respectively. In a subsequent study by the same group [20], KSPC were produced by in-mold reactive injection molding of PA6 (designated as NYRIM) and powder coating/compression molding (PCCM) of knitted textile reinforcements. The effect of the reinforcement's structure and the fiber volume fraction on the mechanical properties of the KSPC resulting from the two methods were investigated and compared. The PCCM process produced SPC laminated with good mechanical properties in tension, reaching relative improvements of the elastic modulus of $12 \%$ and $86 \%$ as compared to the neat PA6 matrix component and KSPC prepared by NYRIM technique.

Despite of the interest to PA6-based SPC, to the best of our knowledge no one so far has systematically studied the recyclability of PA6 based SPC focusing on their mechanical and thermal properties. In the present study PA6-based SPC reinforced by plain-woven textiles (designated as WSPC) were prepared by either NYRIM or PCCM. In the latter case, for the powder-coating of the PA6 woven textiles PA6 microparticles (MP) were used, being previously synthetized from ECL by solution/precipitation AAROP. The reason for selection of these two techniques lied on widening the processing temperature and to avoid degradation of the reinforcements. The tensile properties and the morphological characteristics of the laminates resulting from the NYRIM (N-WSPC) and PCCM (P-WSPC) were evaluated and compared. Subsequently, the fractured composites were injected molded to provide the recycled samples. The bonding state at the reinforcementmatrix interface was investigated by polarizing light microscopy (PLM) coupled with image processing techniques. Finally, in order to access the recyclability, all $\mathrm{N}$ - and P-laminates were mechanically grinded, reprocessed by injection molding. Eventually, the reprocessed SPC were strained as similar fashion as SPC and their tensile properties were compared to the ones in anionic PA6 matrix components and hydrolytic commercial PA6 neat material. Also, the thermal stability of produced and recycled composites was studied in the $30-550{ }^{\circ} \mathrm{C}$ range.

\section{Experimental}

\subsection{Materials}

Plain woven fabrics with air jet textured PA6 continuous filament (160 dtex) were fabricated and delivered from Jackob Müller AG (Switzerland) and pre-washed with non-ionic detergent solution at $30{ }^{\circ} \mathrm{C}$ for $30 \mathrm{~min}$ to reduce contaminations and then rinsed with reverse osmosis water for another $15 \mathrm{~min}$. All woven reinforcements were immersed in acetone for $30 \mathrm{~min}$ and then dried for $120 \mathrm{~min}$ at $60^{\circ} \mathrm{C}$ to eliminate any non-chemically bonded hydrophobic finish from the filament surface. To improve mechanical properties and geometrical stability, all reinforcements were extended biaxially to $30 \%$ of their original length using a specially designed metal frame and a screen stretching apparatus. The extended reinforcements were annealed with fixed ends at $170{ }^{\circ} \mathrm{C}$ for $90 \mathrm{~min}$. The geometric characteristics and tensile properties of the textile reinforcements are shown in Table 1. As expected, the stretching-annealing treatment significantly improved the elastic modulus and tensile strength of plain-woven reinforcements (Table 1).

The ECL monomer of reduced moisture (AP-Nylon ${ }^{\circledR}$ caprolactam) is a product of Brüggemann Chemical, Germany. Before use it was dried under vacuum for $1 \mathrm{~h}$ at $23^{\circ} \mathrm{C}$. As activator for AAROP, Brüggolen C20 (C20) from same company was implemented. The anionic initiator sodium dicaprolactamato-bis-(2-methoxyethoxo)-aluminate (DL) was a product of Katchem (Czech Republic). According to the manufacturer data, C20 includes $80 \mathrm{wt} \%$ of ECL-blocked diisocyanate. Toluene, xylene, acetone and methanol solvents (puriss grade) were purchased from Sigma-Aldrich (USA) and used as received.

\subsection{Sample preparation}

Reactive processing routes in which the composite matrix is created in-situ can help overcome the limitations of the melt processing toward PA6-based SPC [21,22]. The (AAROP) belongs to the reaction pathways suitable for in-situ matrix production in which the ring-shaped lactam monomer transforms into high molecular weight polyamide without liberation of by-products [6,23]. Typically, the optimal temperatures for AAROP bulk polymerization of $\varepsilon$-caprolactam (ECL) are between 160 and $180^{\circ} \mathrm{C}$, while the melting point of the PA6 reinforcing elements is typically around $225^{\circ} \mathrm{C}$. This determines a processing window of $40-60^{\circ} \mathrm{C}$ for the preparation of SPC by this method.

The preparation of the N-WSPC laminates is schematically shown in Fig. 1 (lower part, left). The prototype equipment for in-mold AAROP used for the purpose is described in detail in ref. 20. The required number of plain-woven textiles with dimensions $80 \times 80 \times 3 \mathrm{~mm}$ were placed in the mold with the necessary alignment. Separately, $0.33 \mathrm{~mol}$ of ECL was heated to $90^{\circ} \mathrm{C}$ under nitrogen flux and mixed with $1.5 \mathrm{mmol}$ of DL (Fig. 1, left part). After several minutes at temperatures between 90 and $110^{\circ} \mathrm{C}, 0.75 \mathrm{mmol}$ of the activator C20 was added to the mixture at once. The resulting activated monomer/initiator mixture was injected into the preheated to $120^{\circ} \mathrm{C}$ mold, already containing the textile reinforcements. The AAROP process schematized in Fig. 1 (upper 


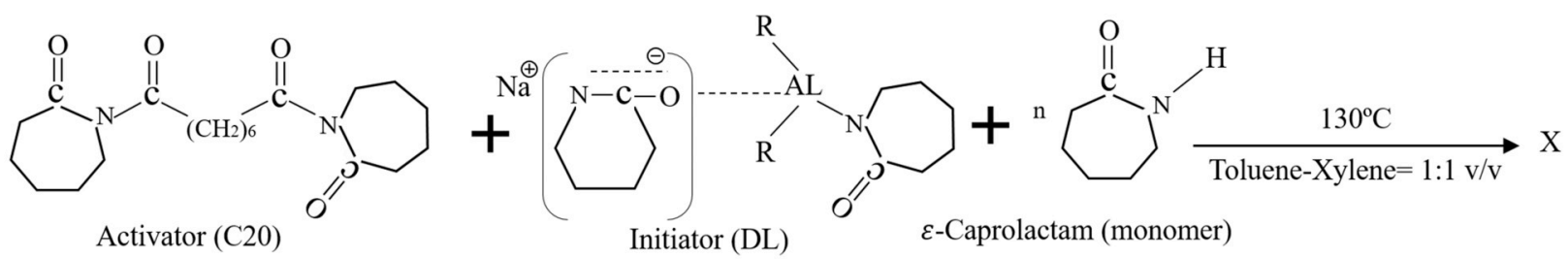<smiles>[X]CC(=O)OC(C)=O</smiles>

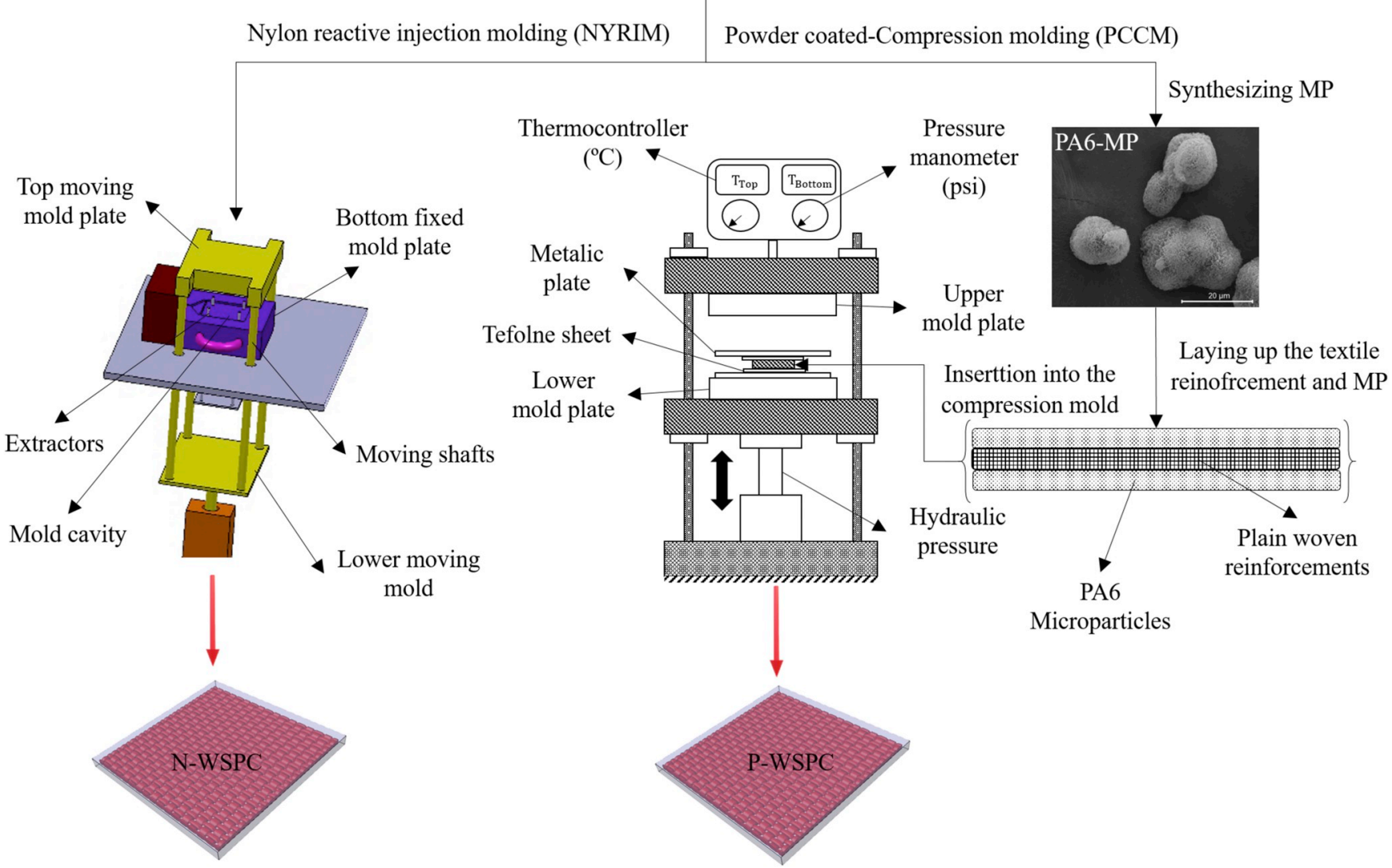

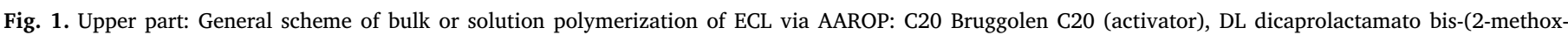

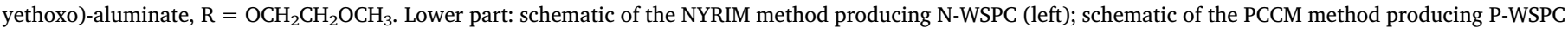
(right).

part) took place at $160-170{ }^{\circ} \mathrm{C}$ during $15 \mathrm{~min}$. Thereafter, the mold was cooled down to $65^{\circ} \mathrm{C}$ at a cooling rate of $40{ }^{\circ} \mathrm{C} / \mathrm{min}$ and the laminate was demolded.

The two-stage PCCM method producing P-WSCP samples is schematized in Fig. 1, lower part, right. First, the PA6 microparticles were synthesized by AAROP in suspension whose general scheme is similar to that shown in Fig. 1, the only difference being that the AAROP was performed not in the bulk but in a mixed toluene/xylene solvent at ca. $120^{\circ} \mathrm{C}$. The same initiator/activator system used in the NYRIM method was applied. The reaction time was $1 \mathrm{~h}$, keeping the temperature in the $125-135{ }^{\circ} \mathrm{C}$ range at constant stirring and refluxing. The microparticles were produced in the form of a fine powder, separated from the reaction mixture by vacuum filtration, washed with methanol, and dried. More details about the chemistry of the process can be found elsewhere [24]. Second, previously calculated amounts of MP were used to powder-coat unidirectional plain-woven textiles, whereby for the preparation of laminate of $\mathrm{Z}$ plies, the microparticles were divided into $(\mathrm{Z}$
+1 ) equal portions. The powder coated textiles were consolidated into P-WSPC in a hot press with mold dimensions of $70 \times 70 \times 2 \mathrm{~mm}$, compression molded at $5 \mathrm{MPa}$ for $10 \mathrm{~min}$ at $215^{\circ} \mathrm{C}$, followed by cooling down to $50{ }^{\circ} \mathrm{C}$ at $50{ }^{\circ} \mathrm{C} / \mathrm{min}$.

For the preparation of both N- and P-WSPC sample sets, three fiber volume fractions $V_{f}$ were used, namely 15,20 , and $25 \mathrm{vol} \%$. The required number of textile plies (N) for each $V_{f}$ value (in \%) was calculated according to Eq. (1) [25].

$N=\frac{V_{f} \rho_{f} Z}{A_{w}} \times 100$

where $\rho_{f},\left(g . \mathrm{m}^{-3}\right)$ is the density of the PA6 filaments, $A_{w},\left(g . \mathrm{m}^{-2}\right)$ is the area density of the textile reinforcement, and $Z(m)$ is the laminate thickness.

For the recycling tests, the fragments of the SPC samples fractured after the tensile test were separated into $\mathrm{N}$ - and P-series. All pieces of 
Table 2

The designation and detail description of WSPC prepared by PCCM and NYRIM.

\begin{tabular}{|c|c|c|c|c|c|}
\hline Material & Molding technique & Designation & $V_{f},(\%)$ & Ply number (PCCM) & Ply number (NYRIM) \\
\hline \multirow[t]{3}{*}{ Neat PA6 } & Injection molding of commercial hydrolytic PA6 & IN & - & - & - \\
\hline & Compression molding of PA6 MP & PN & - & - & - \\
\hline & NYRIM of ECL & $\mathrm{NN}$ & - & - & - \\
\hline \multirow[t]{3}{*}{ WSPC } & PCCM or NYRIM & P-15 or N-15 & 15 & 3 & 6 \\
\hline & & P-20 or $\mathrm{N}-20$ & 20 & 4 & 8 \\
\hline & & P-25 or N-25 & 25 & 5 & 10 \\
\hline \multirow[t]{2}{*}{ Recycled } & PCCM & $\mathrm{RP}$ & - & - & - \\
\hline & NYRIM & $\mathrm{RN}$ & - & - & - \\
\hline
\end{tabular}

Note: MP = PA6 microparticles prepared by AAROP; ECL $=\varepsilon$-caprolactam; $\mathrm{P}$ or $\mathrm{N}$ stand for PCCM or NYRIM.

the same series were combined and grinded, then sieved and cleaned from carbonized material and other contaminations. These granules were then fed into a BOY $22 \mathrm{~A}$ injection molding machine with a clamping force of $220 \mathrm{kN}$, injection piston speed of $40 \mathrm{~mm} / \mathrm{s}$ and maximum injection pressure of $8 \mathrm{MPa}$, operating at $200^{\circ} \mathrm{C}$. Recycled $\mathrm{N}$ and P-WSPC were designated as RN and RP respectively. A commercial PA6 Ultramid ${ }^{\circledR}$ B35 (BASF, Germany) was also injection molded at same conditions and used as a reference sample in the tensile tests (designated as IN). All samples used in this study are summarized in Table 2.

\subsection{Characterization}

The tensile behavior of plain-woven reinforcements was evaluated according to the ASTM D5034 grab test standard method using an Instron 4505 universal testing machine with a standard load cell of $2.5 \mathrm{kN}$ at a constant crosshead speed of $2 \mathrm{~mm} / \mathrm{min}$. The textiles were conditioned at $23^{\circ} \mathrm{C}$ for at least $5 \mathrm{~h}$ before testing. Five woven textile samples with sizes $150 \times 100 \mathrm{~mm}$ were tested in the warp direction. The tensile properties of the N- and P-WSPC laminates, as well as the recycled samples were determined in the same Instron equipment according to ASTM D638. The tests were carried out with a standard load cell of $50 \mathrm{kN}$, at a constant crosshead speed of $2 \mathrm{~mm} / \mathrm{min}$ and temperature of $23 \pm 2{ }^{\circ} \mathrm{C}$. At least five specimens of each sample were tested, previously laser cut to standard dimensions according to ASTM D638.

The morphological characterization was made in an Olympus BH-2 polarizing light microscope equipped with a camera with image acquisition software (Leica Application Suite 4.4). The microscopy images of the monofilaments before and after their embedment into the matrix were converted into binary images. This conversion was made to simplify image thresholding by means of routines from the OpenCV library written in Python. Image processing operations such as erosion and dilation were performed so as to eliminate certain pixels on object boundaries or to smooth concavities.

The thermal properties of the samples were analyzed by combined thermogravimetric (TGA) and differential thermal analyses (DTA) using a modulated TGA Q500 machine from TA Instruments. The method measures the changes of enthalpy while the sample mass is simultaneously decreasing, providing in such a way simultaneous data on the crystallization, melting and degradation of the samples. The analyses were performed in the range of $30-550{ }^{\circ} \mathrm{C}$ in nitrogen atmosphere with a flow rate of $20 \mathrm{~mL} / \mathrm{min}$ and heating ramp of $10^{\circ} \mathrm{C} / \mathrm{min}$. Prior to the test, the samples were dried at $60^{\circ} \mathrm{C}$ for $1 \mathrm{~h}$.

\section{Results and discussion}

\subsection{Tensile tests}

The stress-strain curves from the tensile tests are presented in Fig. 2 and the numerical data extracted from them are tabulated in Table 3. The influence of the fiber volume fractions and the type of the SPC preparation of $\mathrm{N}$ - and P-laminates are shown in Fig. 2a. Judging from the slope of the linear part of the curves, the P-laminates (curves 2-4) have tensile moduli $E$ higher than the neat matrix PN (curve 1). The increase of the fiber content had no significant effect on the stress at break $\left(\sigma_{b r}\right)$ of the P-composites maintaining the values in the range of $50-60 \mathrm{MPa}$, but the strain at break $\left(\varepsilon_{b r}\right)$ grew in respect to the neat PN sample.

As seen from Table 3, all P-laminates had better stiffness, reaching in sample P-15 a ca. 50\% improvement of $E$ as compared to the neat PN reference, and of ca. $98 \%$ in respect to commercial hydrolytic PA6 reference (IN sample), or $86 \%$ as compared to the anionic NN sample. The increase in the $V_{f}$ does not change the $E$-modulus significantly, but causes a clear growth in the $\varepsilon_{\mathrm{br}}$.

The data in Fig. 2a show also that the N-laminate composites (curve 6-8) possess very low $\sigma_{b r}$ values that decrease even more, as the $V_{f}$ grows to $25 \mathrm{vol} \%$. The neat PA6 prepared by NYRIM (curve 5) displays a clear strain hardening region and reaches $\varepsilon_{b r}$ and $\sigma_{b r}$ values of $17 \%$ and ca. $60 \mathrm{MPa}$, respectively. The data in Table 3 confirm the inferior tensile performance of the N-samples, whereby the $E$ and $\sigma_{b r}$ values drop quite significantly as the $V_{f}$ grows.

To explain the above results, a relation was made to our previous study on knitted PA6-based SPC [20] that displayed a similar behavior of the composites prepared by the NYRIM technique. The decreased tensile performance of the latter was attributed to the presence of oligomer fraction in the final SPC. It should be noted that the bulk AAROP of the NYRIM process is highly sensitive to the presence of contaminations, such as fiber finishing found in all PA6 filaments and textiles. Despite the measures taken to eliminate the finishing upon the woven textile structures by washing with acetone, the same decrease was confirmed in the N-composites of the present study (Fig. 2a, curves 6-8). Obviously, some traces of the textile finishing still remained that caused the formation of oligomers during the matrix-forming AAROP. In favor of this supposition is the fact that the NN sample prepared in the absence of textile plies (i.e., no contaminants interfering with AAROP) displayed good tensile properties (Fig. 2a, curve 5, Table 3).

The stress-strain curves in tension of the recycled samples (RP and $\mathrm{RN}$ ) prepared by reprocessing of the respective P- and N- WSPC are presented in Fig. $2 \mathrm{~b}$ and Table 3. The RN sample displays strain hardening combined with relatively low tensile stiffness and yield strengths in the 30-40 MPA range and very high $\varepsilon_{b r}$ close to $130 \%$. The other recycled sample, RP, showed higher $\sigma_{b r}$ of ca. $45 \mathrm{MPa}$ with $\varepsilon_{b r}$ of ca. $40 \%$ evidencing the significant influence of the prior molding technique on the mechanical properties of the recycled composites. Notably, the reprocessed P-WSPC (Table 3 ) with $E=1.8 \mathrm{GPa}$ is clearly stiffer than the commercial neat hydrolytic PA6. This makes the P-WSPC laminates and their recycling an interesting alternative to the conventional fiber reinforced thermoplastics, having in mind the future strategies on waste and recycling [26].

The tensile properties of recycled composites in this study (Fig. 2 and Table 3) were compared to those of injection molded pure hydrolytic PA6 as presented in works of Shan et al. $[27,28]$ and Balamurugan 

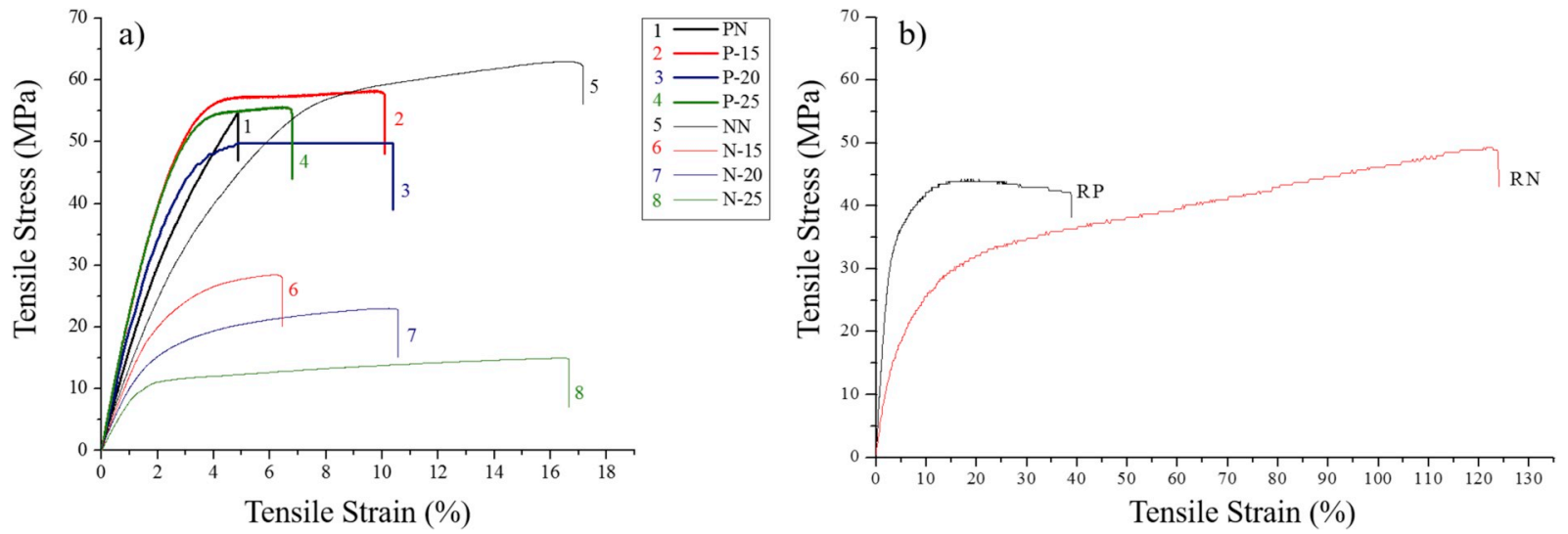

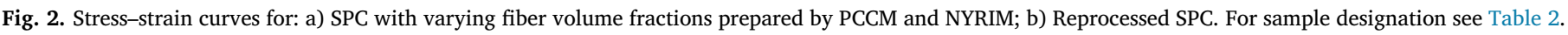

Table 3

Tensile test properties of WSPC prepared by PCCM and NYRIM. For sample designation see Table 2 .

\begin{tabular}{llll}
\hline Samples & $\mathrm{E}(\mathrm{GPa})$ & $\sigma_{\mathrm{br}}(\mathrm{MPa})$ & $\varepsilon_{\mathrm{br}}(\%)$ \\
\hline PN & $1.73 \pm 0.02$ & $56.7 \pm 1.8$ & $5.2 \pm 0.1$ \\
NN & $1.38 \pm 0.05$ & $66.2 \pm 2.9$ & $12.1 \pm 1.1$ \\
IN & $1.30 \pm 0.08$ & $76.4 \pm 1.1$ & $225.7 \pm 3.3$ \\
P-15 & $2.57 \pm 0.03$ & $61.7 \pm 1.1$ & $10.7 \pm 0.5$ \\
P-20 & $2.18 \pm 0.04$ & $51.1 \pm 1.9$ & $11.3 \pm 0.5$ \\
P-25 & $2.41 \pm 0.05$ & $54.3 \pm 1.0$ & $11.3 \pm 0.8$ \\
N-15 & $1.28 \pm 0.07$ & $27.0 \pm 1.4$ & $7.8 \pm 0.1$ \\
N-20 & $1.21 \pm 0.01$ & $23.4 \pm 0.4$ & $11.0 \pm 0.0$ \\
N-25 & $0.94 \pm 0.03$ & $14.4 \pm 0.6$ & $16.2 \pm 0.1$ \\
RP & $1.80 \pm 0.04$ & $43.1 \pm 1.2$ & $38.0 \pm 0.9$ \\
RN & $0.60 \pm 0.02$ & $50.2 \pm 0.9$ & $122.5 \pm 1.4$ \\
\hline
\end{tabular}

et al. [29]. RP samples showed higher tensile stiffness about ca. 80\% and $133 \%$ as compared to neat PA6 material in Refs. [28,29] respectively. It can be therefore concluded that the recycled PA6 based on SPC can be properly recovered from end-of-life products and be employed in any industrial application using commercial injection molded hydrolytic PA6.

\subsection{Microscopy studies}

The relation of the mechanical properties of the composites with the characteristics of the reinforcement/matrix interface was based on PLM observations. Notably, in the P-composites, the matrix is formed by crystallization of the melted MP that takes place in the presence of the oriented filaments of the woven textile structures. In the case of the $\mathrm{N}$ laminates, the PA6 matrix is formed also in the presence of the textile reinforcements, by an in-situ polymerization of ECL where the crystallization starts whenever a critical molecular mass is reached. Under such conditions, a transcrystalline layer (TCL) of matrix PA6 is expected to form at the oriented monofilament surface in both $\mathrm{P}$ - and $\mathrm{N}$ - laminates. The structure and geometry of the TCL can influence the mechanical performance of the composite [30].

Theoretically, as compared to the matrix, the TCL has higher degree of order resulting from a preferred alignment of crystallites. The latter is characterized by a particular distribution and orientation of spherulites along the $c$-axis of the unit cell i.e., in a direction transversal to the nucleating surface [18]. On molecular level, the existence of strong covalent bonds in the polymer chain governs the physical and mechanical properties in this direction. The weaker intermolecular van der Waals interactions and hydrogen bond formation are a result from the orientation of spherulites in perpendicular directions i.e., along the $a$ - a)

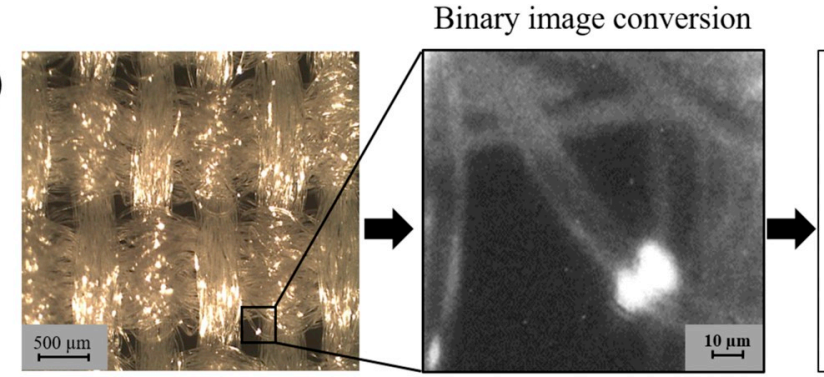

Erosion and Dilation
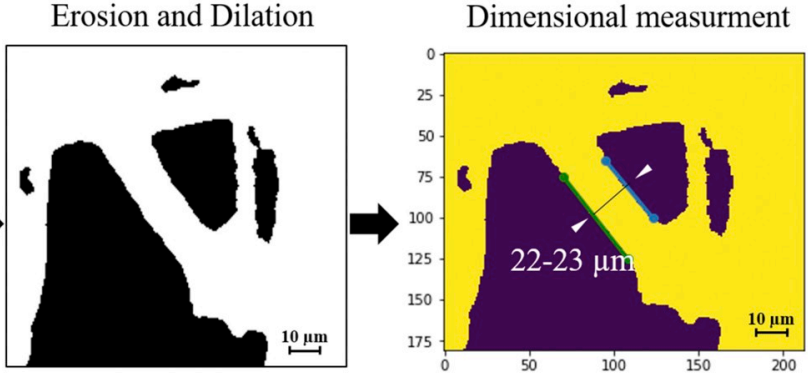

b)

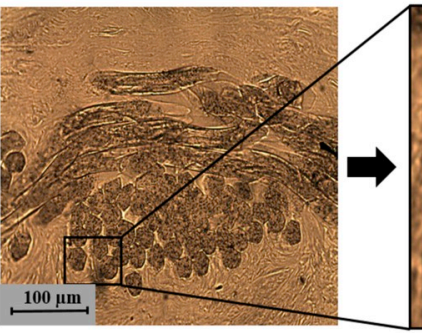

Binary image conversion

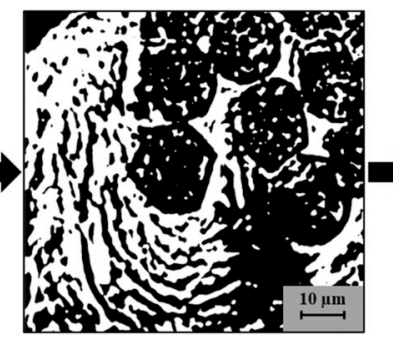

Erosion and Dilation

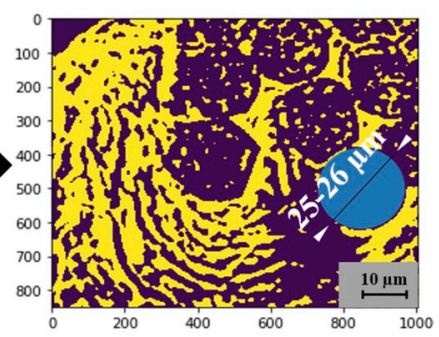

Dimensional measurment

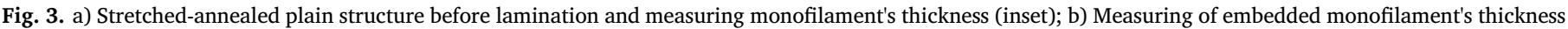
in P-15 sample using Open CV library. 


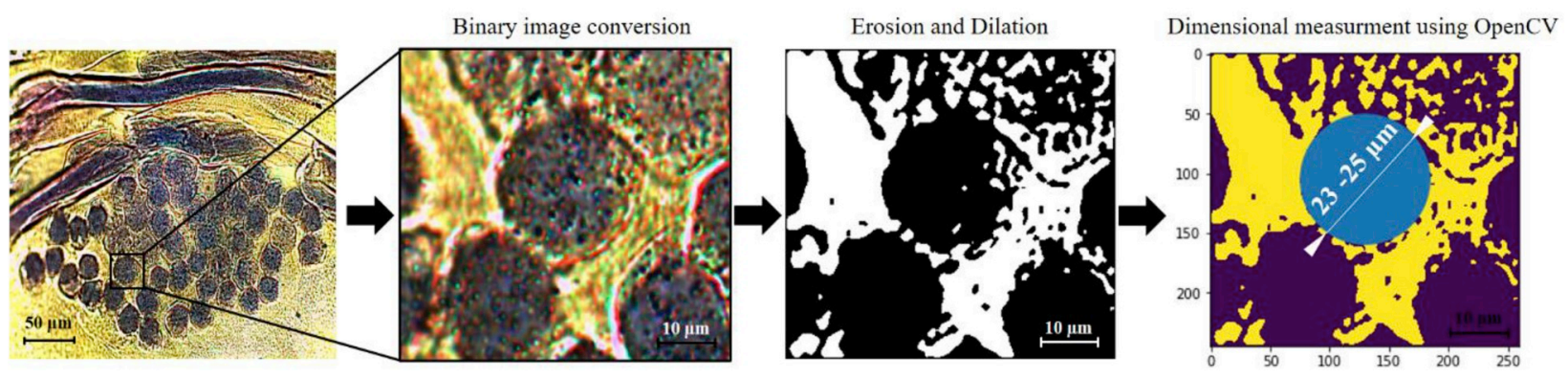

Fig. 4. Image processing of microscopic images of surface topography of N-15 at two different magnifications.

and $b$-axes [31]. Therefore, it can be expected that the mechanical properties of final composites will be determined by the presence of TCL and its shape.

To examine the TCL, the initial thickness of the PA6 monofilaments in the woven textile reinforcement was measured before and after the formation of the matrix (Fig. 3). Fig. 3a shows the micrograph of a stretched-annealed plain-woven textile and the image processing stages applied to outline better the thickness of the monofilament. An average thickness of $22-23 \mu \mathrm{m}$ of the original monofilaments was determined as the mean of five measurements in different zones of the binary image using Matplotlib interface of Python. As seen in Fig. 3b, the average thickness of the matrix-embedded monofilaments in sample P-15 was taken in the same way finding values of $25-26 \mu \mathrm{m}$. According to this observation, the TCL thickness in the P-15 samples should be $1-2 \mu \mathrm{m}$.

Fig. 4 depicts the microscopy and morphological transformation images of N-WSPC where the average thickness of the embedded monofilament was $23-25 \mu \mathrm{m}$. This means that in the N-laminates the thickness of the TCL was around $1 \mu \mathrm{m}$, i.e., slightly lower than in the Plaminates.

Similar values were reported previously in $\operatorname{KSPC}$ materials $[19,20]$ containing knitted textile reinforcement. The average thickness of TCL in P-KSPC and N-KSPC laminates lied between 2-3 $\mu \mathrm{m}$ and $0.5-1 \mu \mathrm{m}$ respectively. The explanation of the TCL thickness in the P- and N-laminates may be related with the pressure during the SPC consolidation, being higher in the case of P-SPC. Furthermore, the cooling rate in NSPC was with $10-15^{\circ} \mathrm{C} / \mathrm{min}$ slower than in the P-composites, which might also had influenced the TCL geometry.

\subsection{Thermal characterization by combined TGA/DTA}

Thermal characterization of PA6 based SPC and the recycled composites was carried out to detect the threshold temperatures in the fabrication process applied. Thermal degradation of PA6 has been studied sufficiently [32-35] showing that it is strongly depended on the temperature and the presence of a nucleophile (i.e. water). Thermal degradation of PA6 begins typically by ECL monomer formation and below $300^{\circ} \mathrm{C}$ in absence of a nucleophile. This occurs by intramolecular end-group cyclization (aminolysis or end-biting) and cyclization (acidolysis or back-biting) within the polymer main chain [32]. The presence of nucleophile leads to a severe reduction in polymer molecular mass and an increase in monomer formation and polymer endgroups concentration.

Fig. 5 represents the combined TGA/DTA curves of P-A, PN, P-15 and RP samples. They display three different thermal characteristics as a function of the temperature, namely the weight loss (TGA, \%), the enthalpy/entropy changes (DTA, $\mu \mathrm{V}$ ) and the derivative of the TGA curve (DTG, $\mu \mathrm{g} / \mathrm{min}$ ). As seen in Fig. $5 \mathrm{a}$, three characteristic points can be observed in each of the graphs. The initial decomposition temperature (IDT) represents the onset of the weight losses, TM is the melting temperature, and MRDT is the temperature of maximum degradation rate.

The DTA traces (red) of the annealed textile structure (P-A) produced from hydrolytic commercial PA6 showed a TM at $216^{\circ} \mathrm{C}$ and a multiple endotherm of thermal degradation centered around $440^{\circ} \mathrm{C}$ (Fig. 5a). The melting peak of the neat PN (Fig. 5b) produced by compression molding of PA6 microparticles was centered at ca. $200{ }^{\circ} \mathrm{C}$ and a strong thermal decomposition at 330 was observed, i.e., a lower thermal resistance of the PN in respect to P-A was found. The RP and P15 sample (Fig. 5c-d) display a DTA behavior similar to that of PN, which is to be expected, having in mid that the matrix of these materials is based on PN.

The data from TGA/DTA analyses of all samples are presented in Table 4. The IDT of the NN and PN matrices was in the range of $249-255{ }^{\circ} \mathrm{C}$ which is with about $50^{\circ} \mathrm{C}$ lower than the IDT of the neat textile reinforcement. Most probably, this difference is due to a higher molecular weight of the PA6 of the textile filaments. The IDT of the P15 laminate sample is comparable to that of the respective neat matrix $\mathrm{PN}$, while the degradation of the $\mathrm{N}-15$ laminate started at temperature about $50{ }^{\circ} \mathrm{C}$ lower than the decomposition of the NN neat PA6. This fact supports the statement made in the previous section that during the NYRIM process carried out in the presence of textile reinforcements, a considerable oligomer PA6 fraction is formed. Apparently, it deteriorates not only the tensile properties but also the thermal stability of the resulting composite.

Regarding the melting temperature, it can be seen that TM of the laminates is comparable to that of the respective neat matrices or a little higher than in the case of P-15 sample. However, both TM values were significantly lower than the melting point of IN reference sample. This fact can be related to a lower molecular weight of the PA6 matrix material in the laminates, on one hand, and to the more precise temperature control during the injection molding leading to better crystalline profile of IN sample, on the other.

From Fig. 5d and Table 4 can be also seen that both of the recycled $\mathrm{RP}$ and RN samples show similar thermal characteristics that are comparable to those of the source composites. The IDT of the RN sample was even about $50{ }^{\circ} \mathrm{C}$ higher than IDT of N-15 laminate. Most probably the injection molding applied for the RN preparation led to diminution of the PA6 oligomer fraction inherent of the N-laminates.

Generally, the explanation of the thermal characteristics of all samples studied could be related to differences in the chemical reactions causing thermal degradation. Four main degradation mechanisms are known in polymers, including main-chain scission, cross-linking, side-chain elimination and side-chain cyclization [36]. In thermoplastics including polyamides, the most common decomposition mechanisms involve breaking of bonds in the main polymer chain. These chain scissions may occur at the chain end or at random location of the chain depending on the PA6 matrix synthetic route (hydrolytic polymerization or AAROP), the presence of oligomers, traces of catalysts and/or low molecular finishing substances and stabilizers related to the textile reinforcements.

\section{Conclusions}

Single polymer laminate composites based on PA6 were successfully 

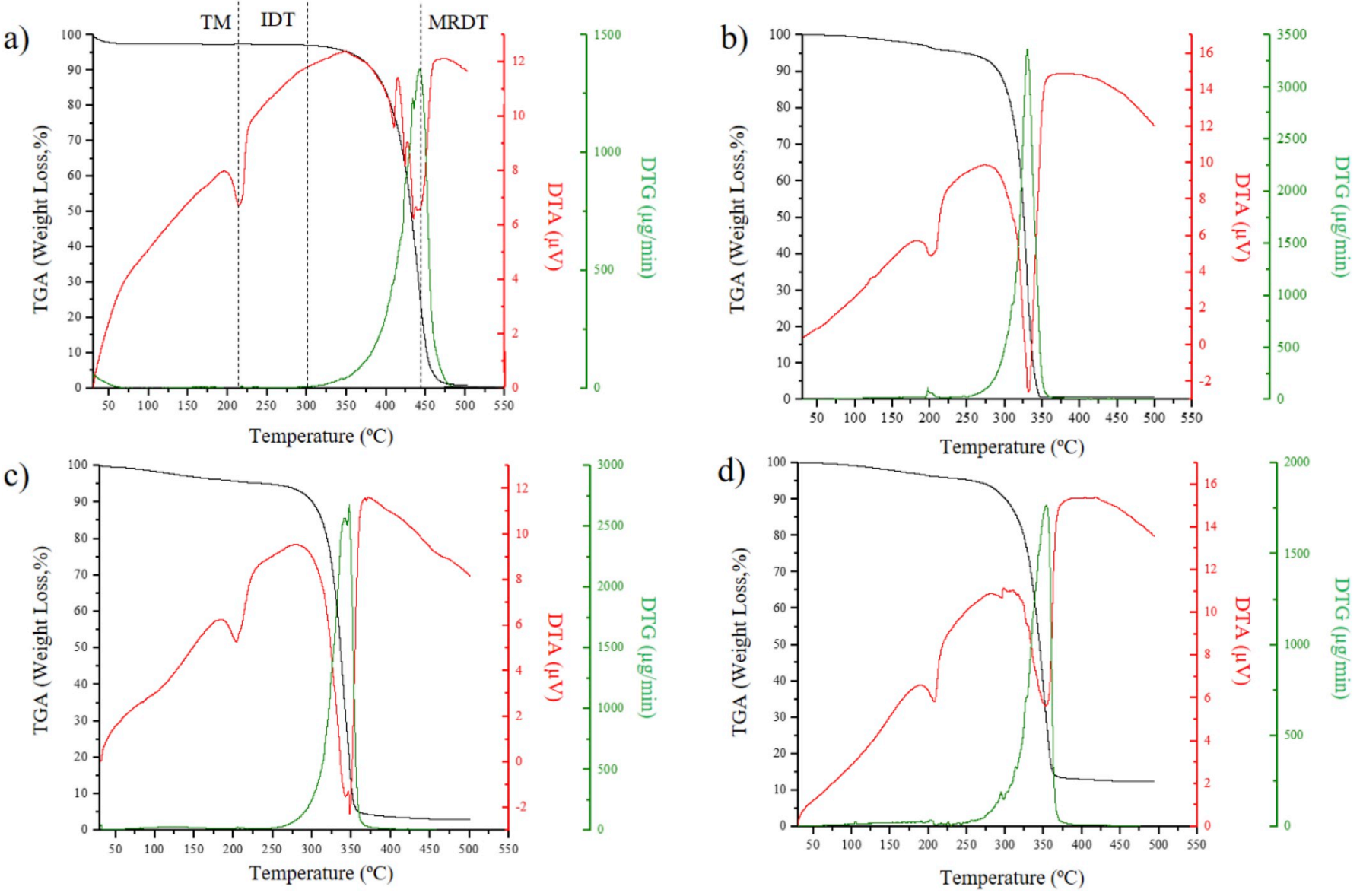

Fig. 5. Combined thermal analyses in $\mathrm{N} 2$ atmosphere at $10^{\circ} \mathrm{C} . \mathrm{min}^{-1}$ heating rate of: a) P-A; b) PN; c) P-15; d) RP. For sample designation see Tables 1 and 2

Table 4

The designation and detail description of WSPC prepared by PCCM and NYRIM. For sample designation see Tables 1-2.

\begin{tabular}{lllll}
\hline Sample & TM $\left({ }^{\circ} \mathrm{C}\right)$ & IDT $\left({ }^{\circ} \mathrm{C}\right)$ & MRDT $\left({ }^{\circ} \mathrm{C}\right)$ & Weight loss, (\%) \\
\hline IN & 220 & 331 & 451 & 98.2 \\
PN & 198 & 249 & 330 & 98.0 \\
NN & 208 & 255 & 317 & 92.0 \\
P-A & 216 & 302 & 441 & 95.4 \\
P-15 & 204 & 252 & 346 & 92.7 \\
N-15 & 208 & 208 & 334 & 90.3 \\
RP & 207 & 254 & 353 & 82.9 \\
RN & 205 & 253 & 347 & 91.6 \\
\hline
\end{tabular}

Notes: $\mathrm{TM}=$ Melting temperature; IDT $=$ Initial decomposition temperature; MRDT $=$ Temperature of maximum degradation rate.

prepared by two molding techniques, namely powder-coating/compression molding (P-composites) or reactive injection molding $(\mathrm{N}$ composites), both carried out in the presence of PA6 plain-woven textile reinforcements. The two SPC types were successfully reprocessed by injection molding to get neat recycled PA6. They were mechanically/ thermally characterized in order to quantify the full recyclability of WSPC. The P-laminates displayed better mechanical properties, whereby the Young's moduli in tension were up to $150 \%$ higher and the stress at break values up to $250 \%$ higher than those of the N-composites, depending on the fiber volume fraction.

A transcrystalline layer at the matrix-fiber interface was observed in both P- and N-composites. By means of image processing, the superior tensile properties of P-composites were attributed to the slightly ticker $\mathrm{TCL}$ at the matrix/reinforcement interface region when compared with
N-composites. The P-15 sample showed also a higher thermal stability, its initial degradation temperature being with $50^{\circ} \mathrm{C}$ lower than of the $\mathrm{N}$ 15 sample. This better performance of the P-laminates was ascribed to the unavoidable existence of oligomer fraction in all N-laminates.

The recycled P-composites displayed tensile stiffness even higher than the commercial hydrolytic PA6 control samples. The recycled samples had thermal properties comparable to those of the respective anionic PA6 references. As a whole, the PA6-based SPC obtained by powder coating/compression molding display good thermal and mechanical characteristics both before and after reprocessing.

\section{Acknowledgements}

This work was partially financed by FEDER funds through the COMPETE program and by national funds through FCT - Foundation for Science and Technology within the project .POCI-01-0145-FEDER007136 SDT thanks FCT for his PhD Grant SFRH/BD/94759/2013. ZZD and NVD thank the National Funds through FCT-Portuguese Foundation for Science and Technology, project reference UID/CTM/50025/2019. All authors gratefully acknowledge the support of the project TSSiPRONORTE-01-0145-FEDER-000015 funded by the regional operational program NORTE 2020, under the PORTUGAL 2020 Partnership Agreement, through the European Regional Development Fund.

\section{Appendix A. Supplementary data}

Supplementary data to this article can be found online at https:// doi.org/10.1016/j.polymertesting.2019.106017. 


\section{Data availability statement}

The raw/processed data required to reproduce these findings cannot be shared at this time due to legal or ethical reasons.

\section{References}

[1] Y. Yang, R. Boom, B. Irion, D.-J. van Heerden, P. Kuiper, H. de Wit, Recycling of composite materials, Chem. Eng. Process. Process Intensif. 51 (2012) 53-68.

[2] G. Schinner, J. Brandt, H. Richter, Recycling carbon-fiber-reinforced thermoplastic composites, J. Thermoplast. Compos. Mater. 9 (1996) 239-245.

[3] M.L. Maspoch, H.E. Ferrando, J.I. Velasco, Characterisation of filled and recycled PA6, Macromol. Symp, Wiley Online Library, 2003, pp. 295-304.

[4] F.P. La Mantia, D. Curto, R. Scaffaro, Recycling of dry and wet polyamide 6, J. Appl. Polym. Sci. 86 (2002) 1899-1903.

[5] M.J. Lozano-González, M.T. Rodriguez-Hernandez, E.A. Gonzalez-De Los Santos, J. Villalpando-Olmos, Physical-mechanical properties and morphological study on nylon-6 recycling by injection molding, J. Appl. Polym. Sci. 76 (2000) 851-858.

[6] J. Karger-Kocsis, T. Bárány, Single-polymer composites (SPCs): status and future trends, Compos. Sci. Technol. 92 (2014) 77-94.

[7] O.A. Khondker, T. Fukui, M. Inoda, A. Nakai, H. Hamada, Fabrication and mechanical properties of aramid/nylon plain knitted composites, Compos. Part A Appl. Sci. Manuf. 35 (2004) 1195-1205.

[8] D. Yao, R. Li, P. Nagarajan, Single-polymer composites based on slowly crystallizing polymers, Polym. Eng. Sci. 46 (2006) 1223-1230.

[9] R.A. Ilyas, S.M. Sapuan, M.R. Ishak, E.S. Zainudin, Development and characterization of sugar palm nanocrystalline cellulose reinforced sugar palm starch bionanocomposites, Carbohydr. Polym. 202 (2018) 186-202.

[10] R.A. Ilyas, S.M. Sapuan, M.R. Ishak, Isolation and characterization of nanocrystalline cellulose from sugar palm fibres (Arenga Pinnata), Carbohydr. Polym. 181 (2018) 1038-1051.

[11] F.V. Lacroix, M. Werwer, K. Schulte, Solution impregnation of polyethylene fibre/ polyethylene matrix composites, Compos. Part A Appl. Sci. Manuf. 29 (1998) 371-376.

[12] P.J. Hine, A. Astruc, I.M. Ward, Hot compaction of polyethylene naphthalate, J. Appl. Polym. Sci. 93 (2004) 796-802.

[13] I.M. Ward, P.J. Hine, The science and technology of hot compaction, Polymer 45 (2004) 1413-1427.

[14] Y. Gong, G. Yang, Single polymer composites by partially melting recycled polyamide 6 fibers: preparation and characterization, J. Appl. Polym. Sci. 118 (2010) $3357-3363$.

[15] D. Bhattacharyya, P. Maitrot, S. Fakirov, Polyamide 6 single polymer composites, Express Polym. Lett. 3 (2009) 525-532.

[16] B. Alcock, N.O. Cabrera, N.-M. Barkoula, Z. Wang, T. Peijs, The effect of temperature and strain rate on the impact performance of recyclable all-polypropylene composites, Compos. B Eng. 39 (2008) 537-547.

[17] Y. Gong, A. Liu, G. Yang, Polyamide single polymer composites prepared via in situ anionic polymerization of $\varepsilon$-caprolactam, Compos. Part A Appl. Sci. Manuf. 41 (2010) 1006-1011.

[18] N. Dencheva, Z. Denchev, A.S. Pouzada, A.S. Sampaio, A.M. Rocha, Structure-properties relationship in single polymer composites based on polyamide
6 prepared by in-mold anionic polymerization, J. Mater. Sci. 48 (2013) 7260-7273.

[19] S.D. Tohidi, A.M. Rocha, N.V. Dencheva, Z. Denchev, Single polymer laminate composites by compression molding of knitted textiles and microparticles of polyamide 6: preparation and structure-properties relationship, Compos. Part A Appl. Sci. Manuf. 109 (2018) 171-183.

[20] S.D. Tohidi, A.M. Rocha, N.V. Dencheva, A.S. Pouzada, Z. Denchev, Comparative structural and mechanical studies on polyamide 6 knitted-reinforced single polymer composites prepared by different reactive processing techniques, Polym. Compos. 40 (2019) 886-897.

[21] K. Van Rijswijk, H.E.N. Bersee, A. Beukers, S.J. Picken, A.A. Van Geenen, Optimisation of anionic polyamide- 6 for vacuum infusion of thermoplastic composites: influence of polymerisation temperature on matrix properties, Polym. Test. 25 (2006) 392-404.

[22] K. Van Rijswijk, S. Lindstedt, D.P.N. Vlasveld, H.E.N. Bersee, A. Beukers, Reactive processing of anionic polyamide- 6 for application in fiber composites: a comparitive study with melt processed polyamides and nanocomposites, Polym. Test. 25 (2006) 873-887.

[23] Á. Kmetty, T. Bárány, J. Karger-Kocsis, Self-reinforced polymeric materials: a review, Prog. Polym. Sci. 35 (2010) 1288-1310.

[24] N. Dencheva, Z. Denchev, S. Lanceros-Méndez, T. Ezquerra Sanz, One-step in situ synthesis of polyamide microcapsules with inorganic payload and their transformation into responsive thermoplastic composite materials, Macromol. Mater. Eng. 301 (2016) 119-124.

[25] A. Brent, Strong, Fundamentals of Composites Manufacturing: Materials, Methods and Applications, Society of Manufacturing Engineers, Michigan, 2008.

[26] D. Lazarevic, E. Aoustin, N. Buclet, N. Brandt, Plastic waste management in the context of a European recycling society: comparing results and uncertainties in life cycle perspective, Resour. Conserv. Recycl. 55 (2010) 246-259.

[27] G.-F. Shan, W. Yang, B. Xie, Z. Li, J. Chen, M. Yang, Double yielding behaviors of polyamide 6 and glass bead filled polyamide 6 composites, Polym. Test. 24 (2005) 704-711.

[28] G.-F. Shan, W. Yang, M. Yang, B. Xie, Z. Li, J. Feng, Effect of crystallinity level on the double yielding behavior of polyamide 6, Polym. Test. 25 (2006) 452-459.

[29] G.P. Balamurugan, S.N. Maiti, The influence of reactive compatibilization on uniaxial large strain deformation and fracture behavior of polyamide 6 and poly (ethylene-co-butyl acrylate) blends, Polym. Test. 27 (2008) 752-764.

[30] H. Quan, Z.-M. Li, M.-B. Yang, R. Huang, On transcrystallinity in semi-crystalline polymer composites, Compos. Sci. Technol. 65 (2005) 999-1021.

[31] H. Nuriel, N. Klein, G. Marom, The effect of the transcrystalline layer on the mechanical properties of composite materials in the fibre direction, Compos. Sci. Technol. 59 (1999) 1685-1690.

[32] S.V. Levchik, E.D. Weil, M. Lewin, Thermal decomposition of aliphatic nylons, Polym. Int. 48 (1999) 532-557.

[33] B.J. Holland, J.N. Hay, Thermal degradation of nylon polymers, Polym. Int. 49 (2000) 943-948.

[34] F. Parres, J.E. Crespo, A. Nadal-Gisbert, Thermal degradation analysis of polyamide 6 processed at different cycles using sequential pyrolysis, J. Appl. Polym. Sci. 114 (2009) 713-719.

[35] R.D. Davis, J.W. Gilman, D.L. VanderHart, Processing degradation of polyamide 6/ montmorillonite clay nanocomposites and clay organic modifier, Polym. Degrad. Stab. 79 (2003) 111-121.

[36] C.L. Beyler, M.M. Hirschler, Thermal decomposition of polymers, SFPE Handb. Fire Prot. Eng., NFPA Quincy, MA, Quincy, Massachusetts, 2002. 